\title{
Creating variability through interspecific hybridization and its utilization for genetic improvement in mungbean [Vigna radiata (L.) Wilczek]
}

\author{
Simranjeet Kaur*, T. S. Bains and Pritpal Singh \\ Department of Plant Breeding and Genetics, Punjab Agricultural University, Ludhiana -141004 (Punjab), INDIA \\ *Corresponding author. E-mail: simransidhu331@gmail.com \\ Received: September 7, 2016; Revised received: February 9, 2017; Accepted: May 15, 2017
}

\begin{abstract}
Interspecific hybridization is important for genetic enhancement of crop plants. The present study was conducted to study genetic variation in advanced interspecific lines of mungbean for yield and its component traits, to determine the association among different traits and their contribution towards seed yield through correlation and path coefficient analysis. A set of 64 genotypes including 51 advanced interspecific lines derived from mungbean (Vigna radiata L. Wilczek) × urdbean (Vigna mungo L. Hepper) and mungbean (Vigna radiata L. Wilczek) $\times$ ricebean (VignaumbellataThumb.) crosses and 13 parents (mungbean, urdbean and ricebean) was the experimental material for this study. The mean sum of squares for genotypes were highly significant for all the traits. Mean sum of squares for replications were also highly significant for all traits except days to $50 \%$ flowering, days to maturity and harvest index at $1 \%$ and $5 \%$ level of significance. This indicated substantial magnitude of diversity and variability in the interspecific lines and parents under study, which could be further exploited. High to moderate PCV and GCV along with high heritability and genetic advance was observed for biological yield per plant, seed yield per plant and plant height, indicating that these traits could be easy targets for phenotypic selection and consequently, may be improved genetically via simple plant selection methods. On the basis of correlation studies, it could be concluded that all the traits under investigation except number of seeds per pod and harvest index were important for selection for yield improvement. Path analysis further revealed that harvest index could also be one of the criteria of selection for higher yield in these interspecific lines.
\end{abstract}

Keywords: Correlation, Interspecific hybridization, Mungbean, Path analysis, Variability

\section{INTRODUCTION}

Mungbean [Vigna radiata (L.) Wilczek] also known as green gram or moong is one of the most important edible food legumes of Asia. In India and some South Asian countries, it contributes significant dietary protein supply to predominantly cereal rich diets. Recently domestic consumption of mungbean has increased because of the rising popularity of Indian ethnic foods and perceived health benefits due to high levels of certain minerals and vitamins (Datta et al., 2012). Mungbean has a very wide adaptability, well suited to a large number of cropping systems and low input requirements. It is also used as green manure and cover crop. Besides its primary use as dal, other preparations such as weaning foods, snacks, noodles and biscuits are also prepared from it. India alone accounts for about two-third of global production with an average area of $3.02 \mathrm{~m}$ ha and production of $1.50 \mathrm{~m}$ tonnes (Anonymous, 2015). The productivity of mungbean is very low i.e. only around $500 \mathrm{~kg}$ per ha. The low productivity can be attributed to narrow genetic base and lack of suitable genotypes for different cropping situations (Dikshit et al., 2009). Interspecific hybridization is important for genetic enhancement of crop plants. The interspecific material thus developed can contribute as genetic reservoir for novel genes apart from contributing to yield and its components. These can also help to widen the genetic base of any crop (Pandiyan et al., 2010). Interspecific hybridization may also serve as an additional source of variation for desirable traits in any crop. Further genetic improvement in quantitative traits can be achieved through a clear understanding of the extent to which desirable traits are heritable. Therefore, information on genetic parameters such as variance, coefficient of variance, heritability and genetic advance of desired traits helps a breeder in efficient utilization of the breeding material. The present study was therefore conducted to study genetic variation in advanced interspecific lines of mungbean (Vigna radiata $\mathrm{L}$. Wilczek) for yield and its components and to determine the association among different traits and their contribution towards seed yield through correlation and path coefficient analysis.

\section{MATERIALS AND METHODS}

A set of 64 genotypes including 51 advanced interspecific lines derived from mungbean (Vigna radiata $\mathrm{L}$. Wilczek) $\times$ urdbean (Vigna mungo L. Hepper) and mungbean (Vigna radiata L. Wilczek) $\times$ ricebean 
(Vignaumbellata Thumb.) crosses and 13 parents (mungbean, urdbean and ricebean) was the experimental material for this study. The experiment was conducted during summer season 2015. These 64 genotypes were sown in paired rows of $3 \mathrm{~m}$ each in simple lattice design $(8 \times 8)$ with two replications and data was recorded for eleven yield and its component traits i.e. days to $50 \%$ flowering, days to maturity, number of branches per plant, plant height, number of clusters per plant, number of pods per plant, number of seeds per pod, seed yield per plant, 100-seed weight, biological yield and harvest index. The analysis of variance for each trait was based on the linear model of Fisher (1954) The genotypic and phenotypic coefficient of variation were calculated as suggested by Burton and Devane (1953) and Johnson et al. (1955). Heritability (percent) in broad sense was calculated by formula given by Allard (1960). Genetic advance was calculated by formula used by Miller et al. (1958). Phenotypic and genotypic correlation coefficient was worked out by the formula suggested by Al-Jibouri et al. (1958). Path coefficient analysis was done following the method of Dewey and Lu (1959).

\section{RESULTS AND DISCUSSION}

Analysis of variance: The analysis of variance of 64 genotypes (interspecific lines and parents) was carried out for eleven morphological traits including seed yield. The ANOVA for lattice design is given in Table 1a. As the block effects of 3 traits i.e. number of pods per plant, seed yield per plant and biological yield per plant were non significant in simple lattice design, therefore the ANOVA for RBD was carried out for these traits (Table 1b). The mean sum of squares for genotypes were highly significant for all the traits. Mean sum of squares for replications were also highly significant for all traits except days to $50 \%$ flowering, days to maturity and harvest index. This indicated substantial magnitude of diversity and variability in the interspecific lines and parents under study, which could be further exploited. Singh and Bains (2014) undertook a study to asses genetic variation and evaluate advance interspecific derivatives of mungbean for yield components. A wide range of variability was observed in all the derivatives for yield and its components under study. The promising parameters were plant height, number of seeds per pod, days to $50 \%$ flowering, harvest index, biological yield, number of pods per plant.

Components of variation: The entire success of plant breeding programme of any crop largely depends on the wide range of variability present in that crop. It is the range of genetic variability in respect of important economic characters present in the population upon which the effectiveness of selection is based. Environment has a profound influence upon the economically important characters which are quantitatively inherited.

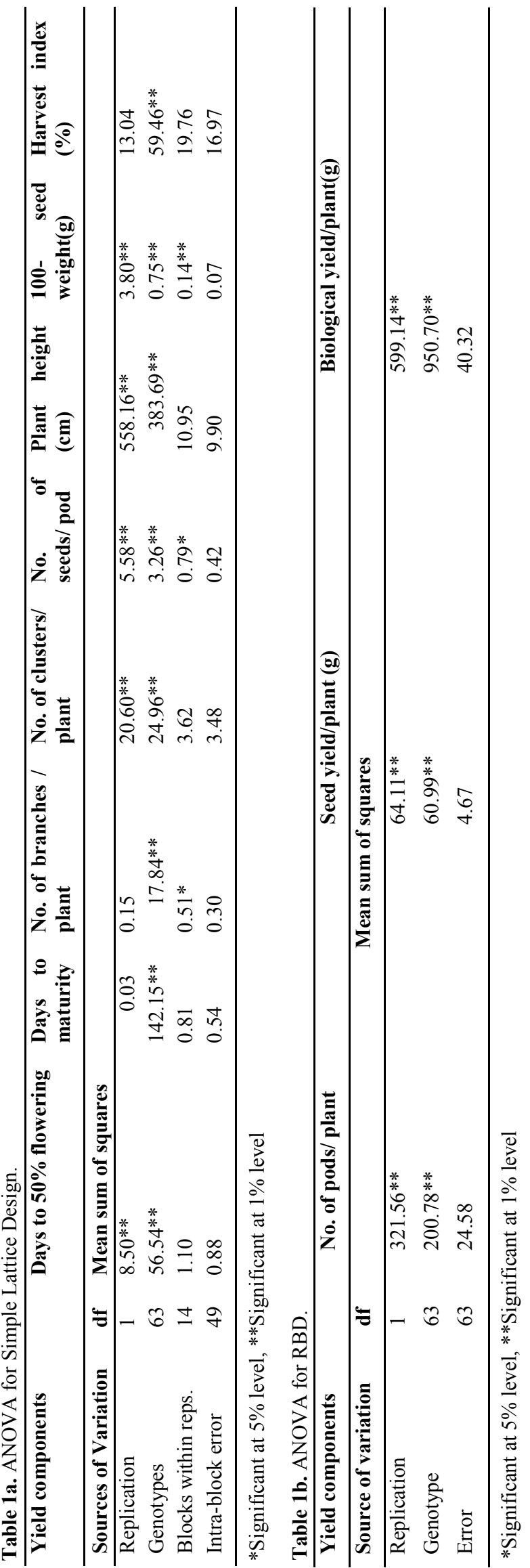


Table 2. Estimates of phenotypic coefficient of variation (PCV), genotypic coefficient of variation (GCV), heritability and genetic advance in interspecific lines in mungbean.

\begin{tabular}{lccccc}
\hline Characters & PCV (\%) & GCV (\%) & $\mathbf{h}^{\mathbf{2}} \mathbf{( \% )}(\mathbf{b . s})$ & GA (\%) & GA(\% of mean) \\
\hline Days to 50\% flowering & 14.68 & 14.44 & 96.74 & 10.68 & 29.25 \\
Days to maturity & 12.80 & 12.75 & 99.16 & 17.26 & 26.15 \\
No of branches/plant & 28.41 & 17.94 & 39.91 & 0.60 & 23.35 \\
No of clusters/plant & 32.19 & 27.93 & 75.31 & 5.85 & 49.93 \\
Number of pods/plant & 29.99 & 26.52 & 78.19 & 17.10 & 48.31 \\
Number of seeds/pod & 13.54 & 11.48 & 71.89 & 1.98 & 20.05 \\
Plant height(cm) & 25.35 & 24.68 & 94.85 & 27.42 & 49.52 \\
Seed yield/plant(g) & 36.96 & 34.23 & 85.77 & 10.12 & 65.30 \\
100 seed weight(g) & 15.31 & 13.64 & 79.41 & 1.08 & 25.04 \\
Biological yield/plant(g) & 46.52 & 44.58 & 91.86 & 42.12 & 88.03 \\
Harvest index (\%) & 18.94 & 13.96 & 54.33 & 6.95 & 21.20 \\
\hline
\end{tabular}

Hence it is difficult to decide upon whether the observed variability is heritable or due to environment and it is therefore necessary to partition the same into its heritable and non-heritable components with suitable parameters like coefficient of variation, heritability estimates and genetic advance. The estimates of phenotypic and genotypic coefficient of variation, heritability in broad sense and genetic advance expressed as percent of mean for yield and its components are given in Table 2. Phenotypic coefficient of variation was high to moderate for biological yield per plant (46.52), seed yield per plant (36.96), number of clusters per plant (32.19), number of pods per plant (29.99), number of branches per plant (28.41) and plant height (25.35). For all other characters it was found to be low. It was also observed that genotypic coefficient of variation was high for biological yield per plant (44.58), seed yield per plant (34.23) and moderate for number of clusters per plant (27.93), number of pods per plant (26.52) and plant height (24.68) but found to be low for all other characters. Results revealed that heritability was very high for days to maturity (99.16), days to $50 \%$ flowering (96.74), plant height (94.85) and biological yield per plant (91.86). It was high to moderate for seed yield per plant (85.77), 100 seed weight (79.41), number of pods per plant (78.19), number of clusters per plant (75.31), number of seeds per pod (71.89) and relatively low for harvest index (54.33). Genetic advance, expressed as percent of mean was high for biological yield per plant (88.03), moderate for seed yield per plant(65.30), number of clusters per plant (49.93), plant height (49.52) and number of pods per plant (48.31). These results were in consonance with many earlier workers. High PCV,GCV and high heritability coupled with high to moderate genetic advance in mungbean was also reported by Begum et al. (2013), Gadakh et al. (2013) and Nand and Anuradha (2013). The same trend was reported in different studies on mungbean by Alom et al. (2014), Ahmad et al. (2014), Raturi et al. (2014), Sahu et al. (2014), Singh et al. (2014) and Patel et al. (2014). Raturi et al. (2015) studied heritability and genetic advance and the number of pods and seed yield were recorded with significantly higher heritability ( $>60 \%$ ), corresponding $\mathrm{PCV}(>25 \%)$ and $\mathrm{GCV}(>20 \%)$ coupled with more than $30 \%$ genetic advance.

A perusal of the results revealed that for all the characters phenotypic coefficient of variation (PCV) were significantly higher than the genotypic coefficient of variation (GCV) and there was narrow differences in their values. This implies that expression of character is mainly governed by the genotypes itself along with a meagre effect of environment. High heritability estimates coupled with high genetic advance was observed for biological yield per plant, seed yield per plant and plant height, indicating greater role of additive gene effects on the expression of these traits which could be easy targets for phenotypic selection and consequently, may be improved genetically via simple plant selection methods. Rest of the traits showed high to moderate heritability coupled with moderate to low genetic advance suggesting the existence of non-additive gene action in the expression of these traits and may be exploited better in recombination breeding.

Correlation and path analysis: Selection procedure is more difficult in a trait where heritability is low or not precisely measurable. Indirect selection in such a situation is more effective and study of correlation among different traits is therefore essential for an effective selection programme because selection for one or more traits results in correlated response for several other traits. Hence the knowledge of phenotypic and genotypic correlation between yield and components characters is very essential. Correlation studies measure only mutual association between two traits and it does not imply the cause and effect of relationship. Path coefficient analysis has been found useful to ascertain direct and indirect causes of association and allows a detailed examination of specific forces acting to produce a given correlation and measure the relative importance of each causal factor.

Phenotypic and genotypic correlation coefficients of different yield parameters are given in Table 3 and path analysis in Table 4 respectively. At phenotypic level seed yield was significantly and positively correlated with biological yield per plant (0.8964), number of pods per plant (0.8320), 
Simranjeet Kaur et al. / J. Appl. \& Nat. Sci. 9 (2): 1101 -1106 (2017)

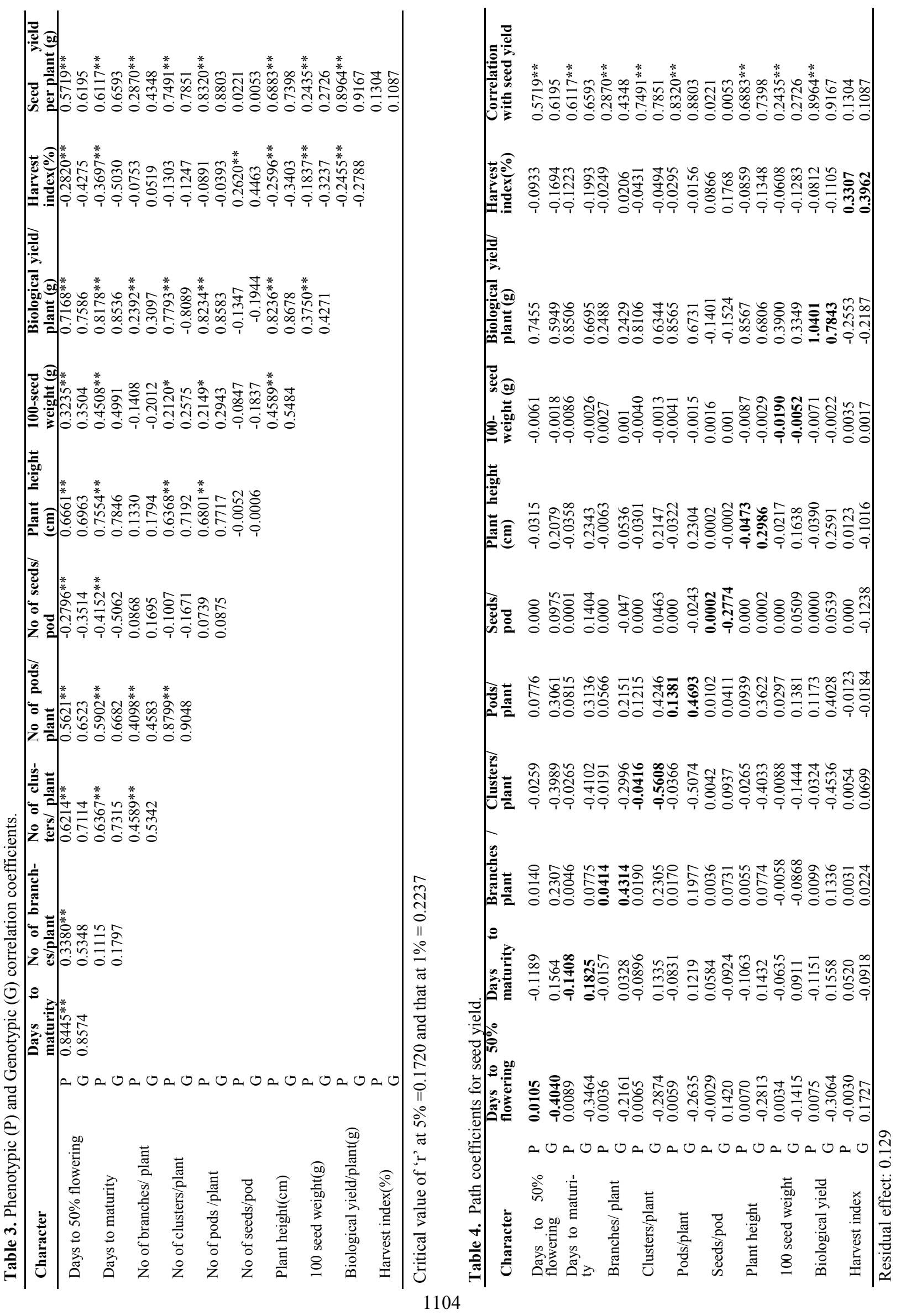


number of clusters per plant $(0.7491)$, plant height (0.6883), days to maturity $(0.6117)$, days to $50 \%$ flowering (0.5719), number of branches per plant (0.2870), days to 50 $\%$ flowering (0.5719), number of branches per plant $(0.2870)$ and 100 seed weight $(0.2435)$. A further perusal of the table reveals that days to $50 \%$ flowering was significantly and positively correlated with days to maturity (0.8445), biological yield (0.7168), plant height (0.6661), number of clusters per plant $(0.6214)$ and number of pods per plant $(0.5621), 100$ seed weight $(0.3235)$ but significantly and negatively correlated with harvest index ($0.2820)$ and number of seeds per pod (-0.2796). Days to maturity was significantly and positively correlated with biological yield $(0.8178)$, plant height $(0.7554)$, number of clusters per plant $(0.6367)$, number of pods per plant (0.5902) and 100 seed weight (0.4508). Days to maturity was significantly and negatively correlated with number of seeds per pod (-0.4152), harvest index (-0.3697).

Further, it was found that number of branches per plant was significantly and positively correlated with number of clusters per plant $(0.4589)$, number of pods per plant $(0.4098)$ and biological yield per plant (0.2392). Number of clusters per plant was significantly and positively correlated with number of pods per plant (0.8799), biological yield (0.7793) and plant height $(0.6368), 100$ seed weight (0.2120). Number of pods per plant was significantly and positively correlated with biological yield per plant (0.8234), plant height (0.6801), 100 seed weight $(0.2149)$. Number of seeds per pod also exhibited significant positive correlation with harvest index (0.2620). Plant height had a significant and positive correlation with biological yield per plant (0.8236) and 100 - seed weight (0.4589) and it was found to be significantly and negatively correlated with harvest index (-0.2596). 100 - seed weight was significantly and positively correlated with biological yield per plant $(0.3750)$ and negatively correlated with harvest index $(-0.1837)$. Biological yield per plant was found to be significantly and negatively correlated with harvest index (0.2455). At genotypic level also the trend was same.

Path coefficient for seed yield parameters in table 4 revealed that at phenotypic level, biological yield per plant (1.0401), harvest index (0.3307), number of pods per plant (0.1381) exerted positive direct effect on seed yield. Days to maturity $(-0.1408)$ exerted negative direct effect on seed yield. At genotypic level also, these parameters showed a direct effect on seed yield. Days to $50 \%$ flowering contributed indirectly and positively to seed yield via biological yield per plant $(0.7455)$. Days to maturity and number of branches per plant also contributed positive indirect effects on seed yield via biological yield i.e. (0.8506) and (0.2488), respectively. Number of clusters per plant contributed indirectly and positively to seed yield through biological yield $(0.8106)$ and number of pods per plant $(0.1215)$. Further, number of pods per plant, plant height and 100 seed weight also showed positive indirect effects on seed yield via biological yield per plant whereas bio- logical yield per plant contributed positive indirect effects on seed yield through number of pods per plant (0.1173). Plant height, biological yield per plant and days to $50 \%$ flowering, exerted negative indirect effects on seed yield through days to maturity $(-0.1063)$, $(-0.1151)$ and $(-0.1189)$ respectively. Days to maturity exerted negative indirect effect on seed yield via harvest index $(-0.1223)$. Further, it was found that number of seeds per pod and harvest index exerted negative indirect effects on seed yield via biological yield ($0.1401)$ and $(-0.2553)$ respectively.

Parsanna et al (2013) showed that primary branches, number of seed yield, number of clusters, and harvest index had a significant and positive correlation with seed yield in mungbean. He also reported that number of pods per plant, number of seeds per pod and days to maturity had maximum positive direct effect towards seed yield. Singh (2014) studied the contribution of different traits towards seed yield through correlation and path analysis in mungbean. Seed yield was significantly and positively correlated with plant height, 100 seed weight, days to $50 \%$ flowering, days to maturity, number of pods per plant, biological yield and harvest index. Hemavathy et al (2015) studied path coefficient on yield and its components in mungbean and found that maximum direct effect on seed yield was observed through number of pods, number of clusters and 100 seed weight. Baisakh et al (2015) reported that plant height, number of clusters, number of pods, pod length and number of seeds per pod showed significant positive correlation with yield. Path-analysis in mungbean showed that number of pods had highest direct positive effects on yield followed by plant height. Positive correlation of most traits with yield was greatly influenced by indirect positive effect via pods plant and plant height.

\section{Conclusion}

The analysis of variance revealed that there were highly significant differences among the genotypes for all the traits. This indicated a substantial magnitude of diversity and variability in the interspecific lines and parents under study, which could be further exploited. Phenotypic coefficients of variation (PCV) and genotypic coefficients of variation (GCV) were high to moderate for biological yield $(46.52,44.58)$, seed yield $(36.96,34.23)$, number of clusters $(32.19,27.93)$, number of pods $(29.99,26.52)$ and plant height $(25.35$, 24.68). Heritability and genetic advance as percent of mean was high for biological yield (91.86, 88.03), seed yield $(85.77,65.30)$ and plant height (94.85, 49.52 ). On the basis of correlation studies it could be concluded that all the traits under investigation except number of seeds per pod and harvest index were important for selection for yield improvement. Path analysis further revealed that harvest index could also be one of the criteria of selection for higher yield in these 
interspecific lines. Therefore, interspecific hybridization may serve as very good tool for creating additional variation for important desirable traits in mungbean. Information on genetic parameters such as variance, coefficient of variance, heritability, genetic advance, correlation and path analysis of advance interspecific lines may help in better utilization of this material for genetic improvement in mungbean.

\section{REFERENCES}

Ahmad, H., Rauf, S., Hussain, I., Rafiq, C., Rehman, A., Moshin, A., Shah baz, U., Sajjad, M. (2014).Genetic variability for yield contributing traits in mung bean (Vigna radiata L.). J Glob Innov Agric Soc Sci., 2(2): $52-54$

Al-Jibouri, H. A., Millar, P. A. and Robinsen, H. F. (1958). Genotypic and environmental variance and co-variance in an upland cotton crop of interspecific origin. Agron $J, 50: 633-36$.

Allard R. W. (1960) Principles of Plant Breeding. John Wiley and Sons, Inc. New York. Pp. 96

Alom, M. M., Rashid, M. H. and Biswas, M. (2014) Genetic variability, correlation and path analysis in mungbean (Vigna radiata L.). J Environ Sci Natural Res., 7:131-38

Anonymous (2015) Project Coordinators Report, All India Coordinated Research Project on MULLARP (ICAR), Indian Institute of Pulses Research, Kanpur: 29.

Baisakh, B., Swain, S. C., Panigrahi, K., Das, T. R., and Mohanty , A. (2015)Estimation of genetic variability and character association in micro mutant lines of greengram (Vigna radiata L.Wilczek) for yield attributes and cold tolerance. Legume Genomics Genet, 7: 1-9

Begum, S., Noor, M., Rahman, H. U., Hassan, G., Ullah, H., Alia and Ali, F. (2013) Heritability estimates and correlations among flowering and yield related traits in mungbean genotypes. British J Appl Sci Technol, 3:472 $-81$

Burton, G. W., and DeVane, E. H. (1953) Estimating heritability in tall Fescue (Festucaarundinacea) from replicated clone material. Agron J, 45: 478-81

Datta, S., Gangwar, S., Kumar, S., Gupta, S., Rai, R., Kaashyap, M., Singh, P., Chaturvedi, S. K., Singh, B. B., and Nadarajan, N. (2012) Genetic diversity in selected Mungbean (Vignaradaita (L.) Wilczek) cultivars using RAPD markers. Am J Plant Sci, 3: 1085-91

Dewey, D. R., and Lu, K. H. (1959) Correlation and path coefficient analysis of component of crested wheat grass seed production. J Agron, 51: 515-18

Dikshit, H. K., Shrama, T. R., Singh, B. B. and Kumari, J. (2009) Molecular and morphological characterization of fixed lines from diverse cross in Mungbean (Vignaradaita (L.) Wilczek). J Genetics, 88: 3

Fisher, R. A., (1954) Statistical Methods for Research Work- ers. Pp. 356. Hafner Publishing Company, Inc, New York.

Gadakh, S. S., Dethe, A. M., and Kathale, M. N. (2013) Genetic variability, correlation and path analysis studies on yield and its components in mungbean (Vigna radiata (L.) Wilczek). Bioinfolet, 10: 441-47

Hemavathy, A., Shunmugavalli, N., and Anand, G. (2015) Genetic variability, correlation and path co-efficient studies on yield and its components in mungbean (Vigna radiata (L.) Wilczek ) Legume Res, 38(4): 442-46

Johnson, H. W., Robinson, H. F., Comstock, R. E. (1955). Estimation of genetic and environmental variability in soybean. Agron J, 47,314-18

Miller, P. A., Williams, J. C., Robinson, H. F. and Comstock, R. E. (1958) Estimates of genotypic and environmental variances and covariance's in Upland cotton and their implications in selection. Agron J, 50: 126-31

Nand, M. J., and Anuradha, C. (2013) Genetic variability, correlation and path coefficient analysis for yield and yield components in mungbean (Vigna radiata $\mathrm{L}$. Wilczek). J Res ANGRAU, 41:31-39

Pandiyan, M., Senthil, N., Ramamoorthi, N., Mithiah, A. R., Tomooka, N., Nuncan, V. and Jayaraj, T. (2010) Interspecific hybridization in Vigna radiata $\mathrm{x} 13$ wild Vignaspecies for developing MYMV donor. Electronic J Pl Breeding, 1: 600-10

Parsanna, B. L., Rao, P. J. M., Murthy, K. G. K. and Parkash, K. K. (2013) Genetic variability, correlation and path coefficient analysis in mungbean. Environ Ecol., 31: 1782-88

Patel, S., Patel, K. and Parmar, H. (2014) Genetic variability, correlation and path analysis for seed yield and its components in green gram (Vigna radiata L. Wilczek) The Bioscan, 9(4) : 1847-52

Raturi, A., Singh, S. K., Sharma, V. and Pathak, R. (2014) Interrelationship among qualitative and quantitative traits in mungbean. Legume Res., 34: 1-10

Raturi, Aparna, Singh, Sharma, S., Vinay and Rakesh, P. (2015) Genetic variability, heritability, genetic advance and path analysis in mungbean (Vigna radiata $\mathrm{L}$. Wilczek) An Int J., 38: 157-63

Sahu, H., Panwar, R., Jeena, A. and Amadabade, J. (2014) Genetic variability and heritability studies in advanced breeding lines of mungbean. Int $J$ Pl Sci.,205-08

Singh, A., Singh, S. K., Sirohi, A. and Yadav, R. (2014) Genetic variability and correlation studies in green gram (Vigna radiata L. Wilczek). Prog. Agric., 9: 59-62

Singh, B. (2014) Exploitation of interspecific hybridization for gentic improvement in mungbean [Vignaradiata(L.)Wilczek]. M.sc. thesis, Punjab Agricultural University, Ludhiana, Punjab.

Singh, B. and Bains, T. S. (2014) Effective selection criteria for yield improvement in interspecific derivatives of mungbean [Vigna radiata $($ L.) Wilczek] IJAR_3359 